\title{
MISTRAL MISTRAL
}

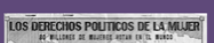

Journal of Latin American Women's

Intellectual \& Cultural History

\section{Solo osos}

\section{Diego Vecchio}

To cite: Diego Vecchio. 2021. "Solo osos.” Mistral: Journal of Latin American Women's Intellectual \& Cultural History 1 (2): 100-105, https://doi.org/10.21827/mistral.2.38031 


\title{
Solo osos
}

\author{
Diego Vecchio
}

Para comenzar a escribir un libro, no hace falta una experiencia, ni un talento, ni una idea, ni siquiera una historia para contar. Para comenzar a escribir un libro, basta tropezar con una palabra. Por ejemplo, OSO. Al igual que otros palíndromos, OSO puede leerse de izquierda a derecha o de derecha a izquierda. Pero OSO tiene un atributo suplementario, ya que también puede rotarse unos $180^{\circ}$ y seguir siendo la misma palabra. Esta figura excepcional es conocida con el nombre de ambigrama.

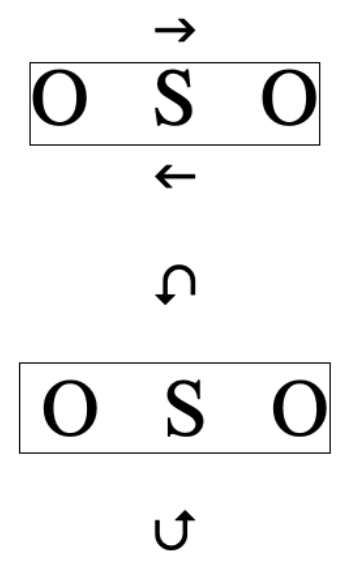

La palabra OSO comenzó a girar en la hélice del lenguaje y de mi imaginación, desplegándose en un relato que tomó direcciones inesperadas, donde se cruzaban el mundo animal, el mundo de la infancia y cierta subcultura gay.

Según Michel Pastoureau, en los tiempos prehistóricos, en grutas y cavernas de Europa, el oso fue adorado como un dios. Vestigios de esta religión ursina se infiltraron en los mitos griegos y en los rituales de los pueblos germánicos, que veneraron en el más grande y poderoso de los mamíferos europeos, no solo al rey de los animales, sino también a un intermediario entre el mundo de los hombres y el de los dioses.

La expansión del cristianismo lo echó todo a perder. Desde la costa africana, donde no había osos, San Agustín lanzó el anatema: ursus est diabolus (el oso es el diablo). En su voluntad de erradicar todo resto de idolatría en los pueblos recientemente convertidos al cristianismo, la Iglesia le declaró abiertamente la guerra al oso, organizando una verdadera persecución que pronto mutó en exterminación. El oso fue destituido como rey de los animales y en su lugar se erigió un impostor oriental: el león. El soberano venido a menos se convirtió, en el bestiario medieval, en un animal tonto, torpe, lujurioso, irascible, felón, gordinflón y ladrón de miel.

El oso terminó vengándose de tantas humillaciones en el siglo XX, metamorfoseándose en el juguete más popular de todos los tiempos, que los padres ofrecieron a sus hijos 
para acompañarlos en los tortuosos caminos del sueño: el oso de peluche. Los niños adoraron a este tótem, volviendo a practicar, sin saberlo, una religión primitiva, que no escapó a los psicoanalistas. Inspirándose en su Majestad el Oso de Peluche, Donald Winnicot elaboró su teoría del objeto transicional, situado en un espacio que no es ni interior ni exterior, predecesor del famoso objeto a lacaniano, que los traductores al español tendrían que haber designado, para hacer justicia al oso, objeto o. En una entrevista, Daniel Bailey le preguntó a Andy Warhol cual fue la persona más excitante con quien estuvo en la cama. Sin titubear, Andy Warhol respondió: mi oso de peluche.

Las palabras no están solas. Una palabra nos lleva a otras palabras; y estas otras palabras, a otras y así hasta el agotamiento. El lenguaje no está solo, replegado sobre sí mismo, como un erizo. El lenguaje está abierto. Las palabras también evocan, invocan y precipitan estados de cosas.

Cuando se puso a girar la hélice de oso, golpearon a la puerta. Era una encomienda, preparada con esmero y enviada desde las montañas por Ana L., con un oso de peluche. Así comenzaron a llegar ejemplares pardos, grises, negros, blancos, amarillos o anaranjados, de pelo suave o áspero, con patas rígidas o articuladas, con sombrero o sin sombrero, con corbata o moño, vestidos con un pullover o púdicamente desnudos, a veces confeccionados a mano, acompañados siempre por una historia, a los que había que darles un nombre y encontrarles un lugar.

Para no ser menos, otros amigos también empezaron a regalarme osos de peluche, de todas formas y colores, para mi cumpleaños, navidad, el 21 de octubre (día de Santa Úrsula, santa que lleva en su nombre la palabra ursus), el 11 de noviembre (día de San Martín, que coincide con el comienzo de la hibernación del oso), el 14 de febrero (día de San Valentín, que coincide con el final del letargo invernal), o simplemente un evento que mereciera festejo.

Un día la novela salió a la calle. Al volver a casa, hallé, asomando de un contenedor de basura reciclada, una inmensa cabeza de oso, desprendida de su cuerpo, a la manera de una escultura olmeca, llamándome y pidiéndome que la incorporara a la colección. Y eso hice, inventando una nueva costumbre, o mejor dicho, un nuevo ritual de la religión ursina extinguida. Cuando alguien venía a casa, para poder pasar del exterior al interior, debía darle un beso a esta cabeza de oso, sin oso.

Hacia la misma época, Leena R. encontró, también abandonados, delante de una obra en construcción, osos de peluche que recogió, lavó y reparó, reconstruyendo un brazo que había sido amputado, cosiendo un ojo de plástico que se había desprendido, rellenando con gomapluma un vientre flácido que había perdido su interior por una desgarradura, antes de ofrecérmelos para fundar un orfelinato de osos de peluche. 


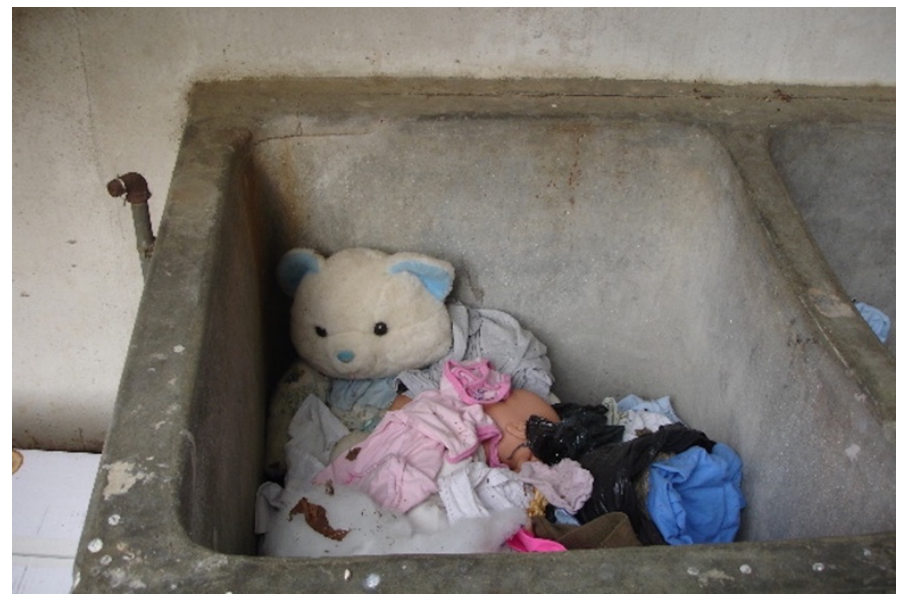

Fui acomodando estos dones primero en mi cama y cuando la cama resultó demasiado estrecha, en dos estanterías que instalé en el dormitorio y cuando ya no hubo más lugar, apilé cuidadosamente a los osos que me iban regalando en un rincón de la casa, formando una montaña de peluche, que no dejaba de crecer y desmoronarse. Sorprendida por la instalación, una visita murmuró por lo bajo: "Pensé que venía a la casa de un escritor, pero me encontré con la casa de un niño".
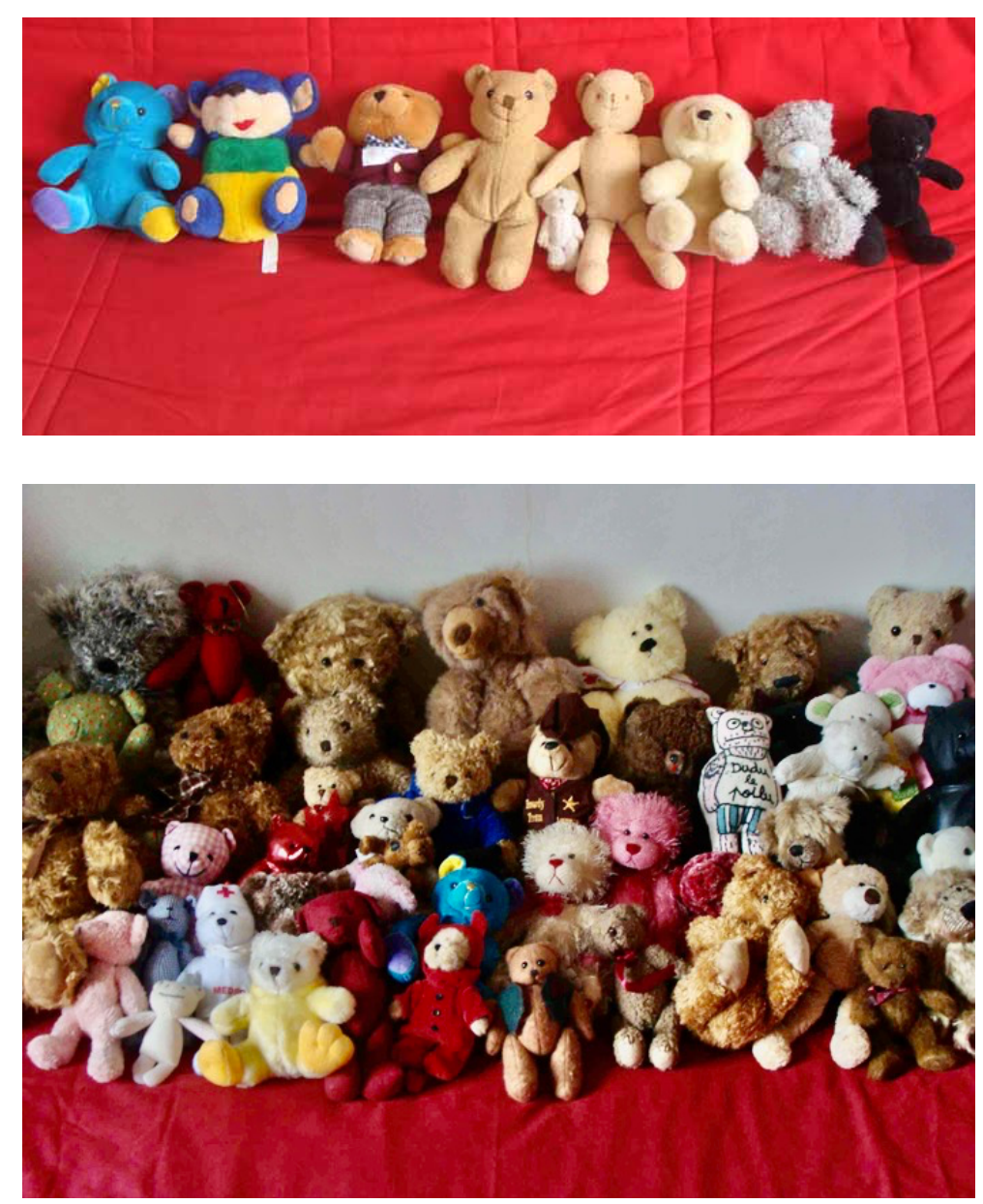


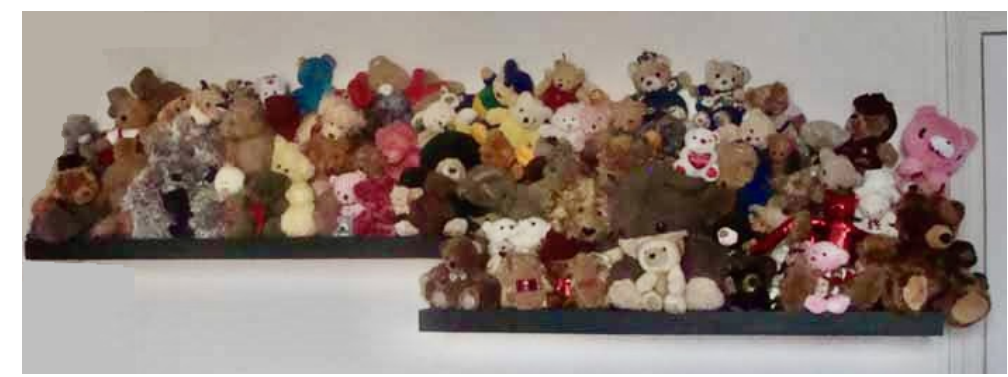

[3]

Al explorar las fronteras de ese espacio resbaladizo llamado literatura infantil, era inevitable retornar a la infancia y volver a formular las preguntas: ¿qué es un niño? ¿qué es la literatura? Los niños, como la literatura y los osos de peluche, son una invención reciente. Nunca resultó muy convincente afirmar que la literatura infantil es la literatura destinada a los niños, escrita por los adultos. ¿Hace falta recordar que muchos de los textos que forman actualmente parte de la literatura infantil al principio no lo fueron y que con demasiada frecuencia los niños son reducidos a los prejuicios y estereotipos que los adultos tienen sobre los niños? Prefiero imaginar que la literatura infantil es aquella que hace retornar, en los adultos, el mundo de la infancia, borrando las fronteras entre las generaciones y las edades.

\section{[4]}

El mundo de la infancia coincide muy a menudo con la era de la angustia. Los osos de peluches son amuletos para conjurar dichos terrores.

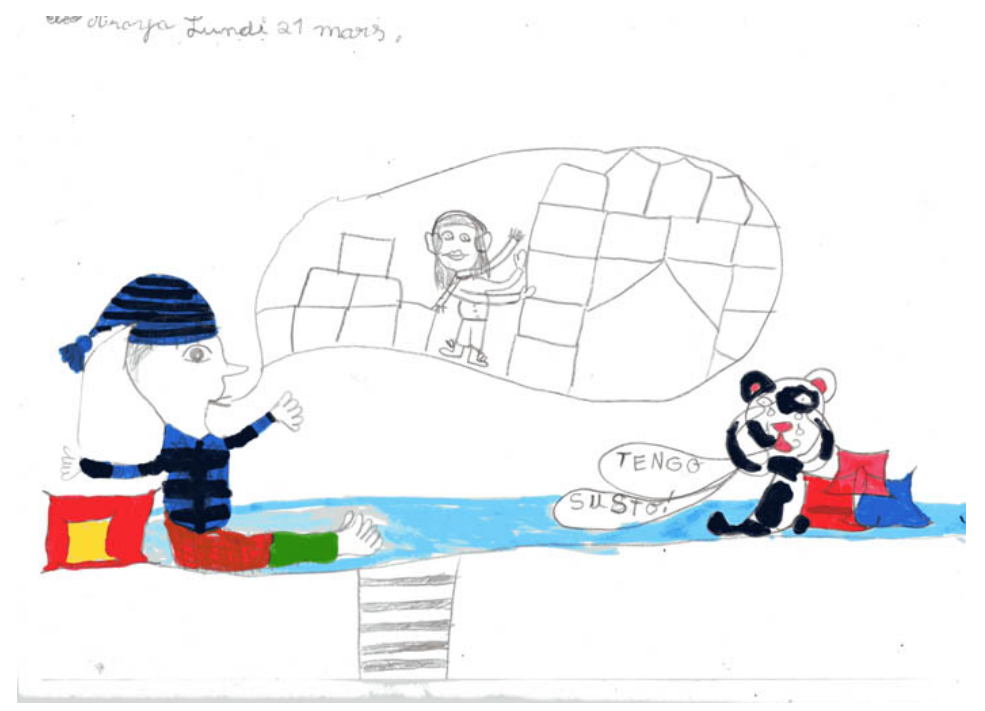

[5]

Cuando ya no quedó más lugar para los osos ni en el libro ni en la casa, tuve que buscar un nuevo espacio y en octubre del 2007, en pleno auge de los "blogs de escritor", abrí soloosos, un blog-juguetería consagrado al mundo ursino, donde fui subiendo 
materiales propios y ajenos; un cuaderno borrador abierto al público las 24 horas, donde apuntaba el rumbo y las maniobras de Osos; una madriguera virtual, donde fui registrando y hospedando a los osos de peluche que ingresaban a la colección.

Según Plinio el Viejo, los osos se acoplan al comienzo del invierno. En lugar de practicar el coitus a tergo, como suelen hacer la mayoría de los cuadrúpedos, prefieren el coito cara a cara para poder besarse hocico con hocico. Un mes más tarde, la osa da luz a una camada de oseznos que no son sino una masa de carne blanca informe, sin ojos ni pelos, del que solo sobresalen las uñas. La madre les da la forma de osos, lamiéndolos.

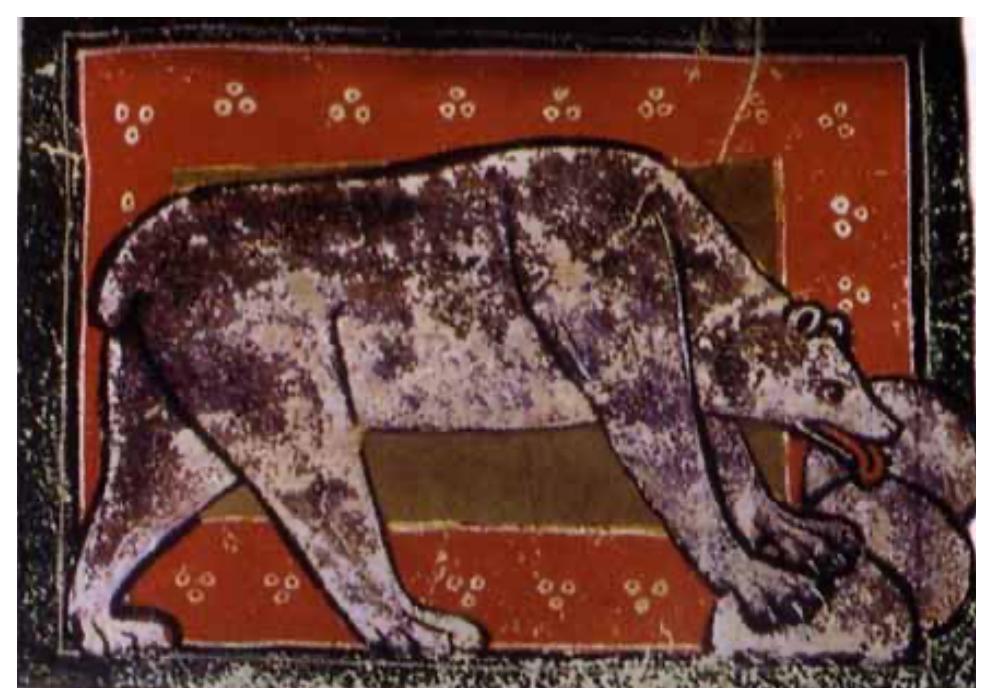

Las semejanzas entre ciertas costumbres ursinas y ciertas prácticas literarias no pasaron desapercibidas. Así como la osa lame a esa masa de carne hasta darle una forma de osezno, del mismo modo se escribe, borrando, tachando, enmendando y reformulando una materia informe. El blog fue una lengua suplementaria para darle forma al libro.

Osos fue publicado en el 2010, por Beatriz Viterbo. Durante un tiempo, el blog siguió albergando los videos de las lecturas y las performances que prolongaron el libro fuera del libro. Como siempre, no se sabe muy bien qué es lo que comienza y qué es lo que termina con las revoluciones tecnológicas. Muchas de las cosas que parecían comenzar en realidad ya estaban terminadas antes del principio. Y al revés: lo que parecía terminado, persistió en existir, con una vitalidad espectral de las que muchas cosas nuevas carecen.

En un abrir y cerrar de ojos, la expansión de las redes sociales hizo del blog una especie obsoleta. Poco a poco, las entradas se fueron espaciando y las visitas comenzaron a declinar. La última entrada del blog fue el 22 de noviembre del 2014 y corresponde a una mesa redonda con Sergio Álvarez, organizada por la mediateca de Valence (Francia) durante el festival Les Belles Latinas.

Como tantos otros blogs de escritor, soloosos se convirtió en un blog fantasma, a la deriva, un sitio arqueológico digital, con restos fósiles de una literatura extinguida. Muchos de los videos o de los enlaces ya no están disponibles. De tanto en tanto, alguien deja un comentario. En realidad, no es un lector, sino una publicidad. 

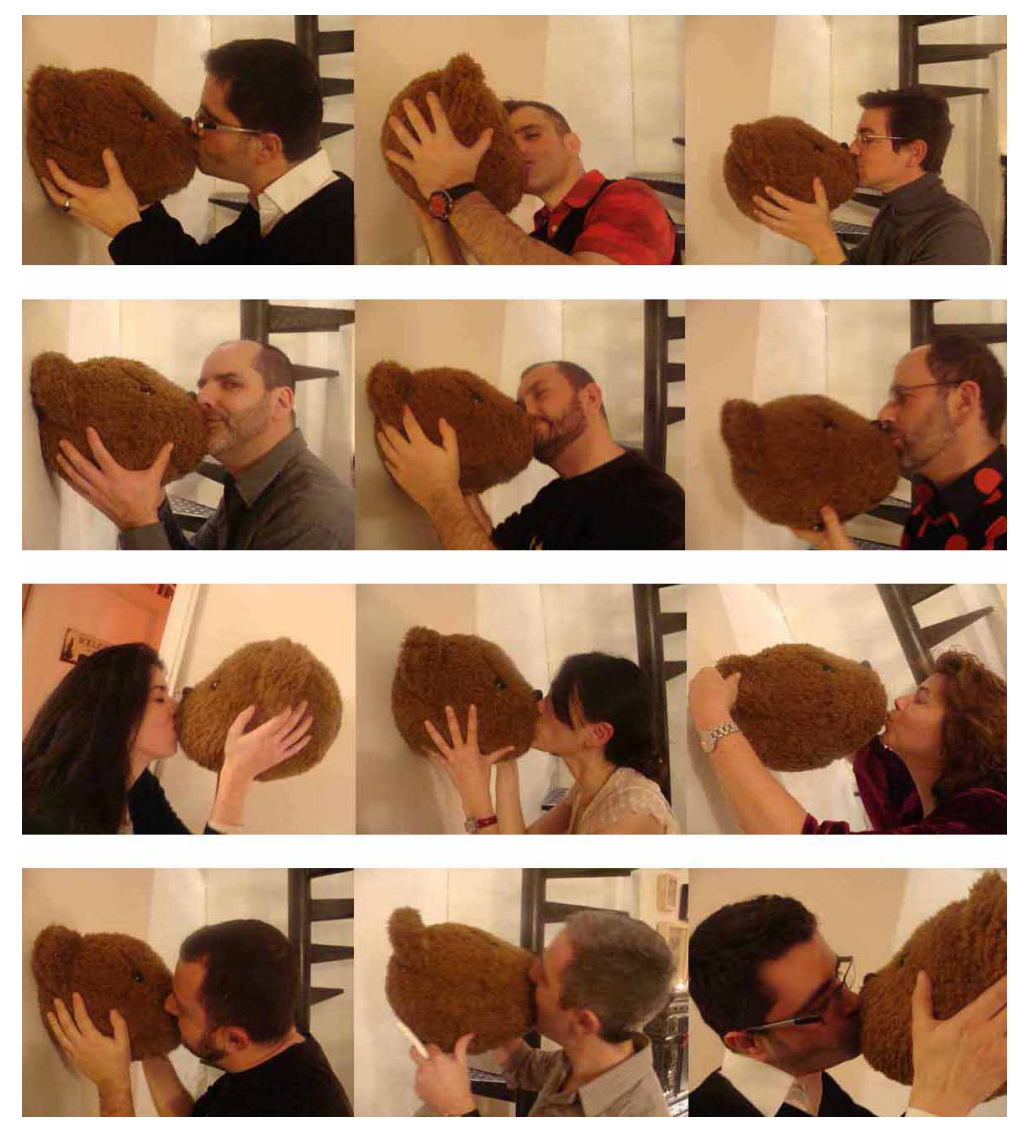